\title{
What is the best way to restore the worn dentition?
}

\author{
Dominic Hurst \\ Queen Mary University of London, Barts \& The London School of Medicine and Dentistry, Institute of Dentistry, 4 New Road, London E1 $2 A T$
}

\section{Background}

Tooth surface loss (TSL) can span from initial enamel loss, though cupping of the occlusal surfaces of posterior teeth, exposure of large areas of dentine on anterior teeth, fractures of unsupported enamel and on until much of the tooth tissue has been lost. $^{1-3}$ In a recent national survey it was found that $15 \%$ of adults showed moderate wear and $2 \%$ severe wear. ${ }^{4}$ Elsewhere it has been estimated that $17 \%$ of those aged 70 years will have severe tooth wear. ${ }^{5}$ The exact aetiology of wear in an individual case may or may not be ascertainable but the quality of life for a patient with TSL may be impeded to such an extent ${ }^{6}$ that they will require us to intervene not only preventively ${ }^{7,8}$ but also restoratively.

A number of materials and approaches have been used to restore the worn dentition. Composite is a versatile material and has expanded from its early role as an aesthetic anterior restorative material to one that is used for localised anterior and even whole-mouth rehabilitation. ${ }^{9-12}$ But there are a number of other materials and approaches to restoring the worn dentition, particularly as larger areas of the occlusal surface become involved. These include using gold, ceramic and laboratory composites to make onlays ${ }^{13,14}$ and crowns, ${ }^{15}$ alone or in combination. ${ }^{16}$

The restoration of teeth with severe wear is clearly complex. Not only does one need to consider the longevity of the restoration but also the effect it may have on the opposing teeth and the effect on the pulp. Furthermore, some restorations may fail catastrophically, whilst others need only be smoothed or repaired. Thus in the ideal world we would expect to find evidence based guidelines ${ }^{17}$ or a systematic review ${ }^{18}$ of randomised controlled trials that would pull these data together and help us clinicians make evidence-based decisions with our patients about how to restore their teeth. In the absence of a systematic review

\begin{tabular}{|c|c|c|}
\hline & Terms & Hits \\
\hline$\# 1$ & $\begin{array}{l}\text { "Tooth Attrition"[Mesh] OR "Tooth Wear"[Mesh] OR "Tooth Erosion"[Mesh] } \\
\text { OR "tooth wear"[tiab] OR "tooth wear"[tiab] OR "tooth attrition"[tiab] OR } \\
\text { "tooth erosion"[tiab] OR "dental wear"[tiab] OR "dental attrition"[tiab] } \\
\text { OR "dental erosion"[tiab] OR "tooth surface loss"[tiab] OR "TSL"[tiab] OR } \\
\text { "bruxism"[tiab] }\end{array}$ & 5802 \\
\hline$\# 2$ & $\begin{array}{l}\text { Meta-Analysis[ptyp] OR "systematic literature"[tiab] OR (systematic[ti] } \\
\text { AND review*[ti]) OR "systematic review*"[tiab] OR meta-analys*[tiab] OR } \\
\text { "cochrane database syst rev"[Journal] OR "cochrane database of systematic } \\
\text { reviews online"[Journal] OR "research synthesis"[tiab] OR "research } \\
\text { integration"[tiab] OR "medline"[tiab] OR pubmed[tiab] OR psyclit[tiab] OR } \\
\text { psycinfo[tiab] OR cinahl[tiab] OR "data synthesis"[tiab] }\end{array}$ & 98403 \\
\hline \#3 & $\begin{array}{l}\text { ((randomized controlled trial[pt]) OR (controlled clinical trial[pt]) } \\
\text { OR (randomized[tiab]) OR (placebo[tiab]) OR (drug therapy[sh]) OR } \\
\text { (randomly[tiab]) OR (trial[tiab]) OR (groups[tiab])) NOT (animals[mh] NOT } \\
\text { humans[mh]) }\end{array}$ & $2,396,101$ \\
\hline$\# 4$ & \#1 AND \#2 & 48 \\
\hline \#5 & $\# 1$ AND \#3 & 962 \\
\hline
\end{tabular}

Table 2. Cochrane Library - final search 29/05/2011

\begin{tabular}{l|l|l} 
& Term & Hits \\
\hline$\# 1$ & (tooth wear):ti,ab,kw & 210 \\
\hline$\# 2$ & (tooth OR dental) AND (attrition OR erosion):ti,ab,kw & 191 \\
\hline$\# 3$ & (tooth surface loss OR TSL):ti,ab,kw & 124 \\
\hline$\# 4$ & MeSH descriptor Tooth Wear explode all trees & 188 \\
\hline$\# 5$ & $(\# 1$ OR \#2 OR \#3 OR \#4) & 510
\end{tabular}

we would like to identify one or more randomised controlled trials that compare two restorative interventions (for example composite versus gold onlays on posterior teeth, or composite versus veneers on anterior teeth).

The objective of this DEBT was to identify evidence-based guidelines, systematic reviews and / or randomised controlled trials that would assist me in answering my question, which is:

In patients with sufficient TSL to warrant restoration (for functional, comfort or aesthetic reasons) which of crowns (gold, ceramic or metal-ceramic), indirect onlays (gold, ceramic or composite) or direct (composite, resin-modified glass-ionomer) onlays result in the longest retention (and causes least damage to the tooth on which it is placed and that opposing it) either alone or in combination?

Eligible reports would be evidencebased guidelines and systematic reviews addressing the restoration of wear, and randomised controlled trials (RCTs) comparing two interventions for the restoration of worn teeth with some measure of longevity or harm to the tooth or opposing tooth as outcomes.

\section{Search strategy}

Given the variable means of restoring the worn dentition (and therefore the large number of possible combinations that could be involved in an RCT) I chose to search using terms related to TSL only. 
This would inevitably mean having a larger number of reports to wade through but would mean the risk of me missing a suitable report is minimised.

Table 1 shows my Pubmed search. Search \#1 is the MeSH and keyword terms related to TSL. Search \#2 is a filter for systematic reviews ${ }^{19}$ and search \#3 a filter for randomised controlled trials. ${ }^{20}$ Search \#4 therefore should include systematic reviews involving TSL and search \#5 should include all trials involving TSL.

In a similar fashion all the databases of the Cochrane Library ${ }^{21}$ were searched. However, because the library already sorts reports into systematic reviews and trials, there was no need to include filters.

Twelve of these were Cochrane Reviews, one was another systematic review, 496 were clinical trials and one was a methodology study.

The Pubmed and Cochrane Library results were merged in Endnote and duplicates removed. One thousand, three hundred and forty reports remained.

The National Guidelines Clearinghouse ${ }^{22}$ was searched using 'Tooth wear' and 'Dental wear' separately. There were 15 and 30 hits, respectively.

TRIPdatabase ${ }^{23}$ was searched with the following string: "tooth surface loss" OR TSL OR (dental AND (attrition OR erosion)) OR ((dental OR tooth) AND wear).

This resulted in 663 hits. Two hundred and seventy two of these included EvidenceBased Synopses - 5, Systematic Reviews - 16, Guidelines - 55 and core or extended primary research - 196. The remaining were text books, patient information and other texts.

All the hits identified in these searches were screened by title and, where necessary for clarification, by linking through to the abstract or full text.

\section{Results}

Two guidelines were identified that addressed tooth sensitivity and erosion. ${ }^{24,25}$ Neither was able to quote evidence higher than expert opinion or observational stud- ies in support of individual restorative measures for the replacement of tooth tissue. Neither was able to recommend one method of intervention over another.

I was unable to identify any systematic reviews that considered restoration of the worn dentition. One randomised controlled trial met the inclusion criteria that two interventions be compared in a randomised controlled trial. ${ }^{26}$ In this split mouth trial 16 patients with severe tooth wear had two teeth randomly allocated to either a direct micro-filled composite or a developmental indirect composite onlay. Of the 32 restorations placed in total seven indirect and nine direct composites were still in place at the end of follow-up - that is $44 \%$ and $56 \%$ respectively. However, there was no statistical difference between these.

Whilst the authors of this study concluded that posterior composites are contraindicated because of this high failure rate, if restoration is required it is difficult to say that any other material would serve any better without a trial comparing composite to, say, gold onlay. The study doesn't demonstrate a difference between the direct and indirect failure rate but this may be due to the low sample size. With greater power and therefore precision this study may have demonstrated a statistically - and clinically significant - difference in favour of the direct composite, or it may not have. Using an online sample size calculator ${ }^{27}$ assuming a $5 \%$ alpha and $20 \%$ beta error, I estimate that 780 restorations would need to be placed in order to demonstrate a statistical difference in success of $10 \%$ between the two materials (55\% direct versus $45 \%$ indirect composite). The scale of the trial would need to be considerably larger.

\section{Conclusion}

Unfortunately, we are in a position of not knowing which restorative option is preferable in terms of longevity, preservation of vitality or minimisation of opposing tooth wear. Trials that compare interventions with small differences in outcome will need to be large enough to demonstrate statistical significance. These would be worthwhile given the potential expense involved in restoring wear cases. At present, though, low level evidence from experts and observational studies, personal clinical experience and patient values are all that are left to guide us.

1. Davies SJ, Gray RJ, Qualtrough AJ. Management of tooth surface loss. Br Dent / 2002; 192: 11-16, 19-23.

2. Jaeggi T, Lussi A. Prevalence, incidence and distribution of erosion. Monogr Oral Sci 2006; 20: $44-65$.

3. Smith BG, Robb ND. The prevalence of toothwear in 1007 dental patients. J Oral Rehabil 1996; 23: 232-239.

4. Dental and Eye Care Team. Disease and related disorders - a report from the Adult Dental Health Survey 2009 London: The NHS Information Centre for health and social care, 2009.

5. Van't Spijker A, Rodriguez JM, Kreulen CM, Bronkhorst EM, Bartlett DW, Creugers NH. Prevalence of tooth wear in adults. Int J Prosthodont 2009; 22: 35-42.

6. Al-Omiri MK, Lamey PJ, Clifford T. Impact of tooth wear on daily living. Int / Prosthodont 2006; 19: 601-605.

7. Lussi A, Hellwig E, Zero D, Jaeggi T. Erosive tooth wear: diagnosis, risk factors and prevention. Am J Dent 2006; 19: 319-325.

8. Holbrook WP, Arnadottir IB, Kay EJ. Prevention. Part 3: prevention of tooth wear. Br Dent J 2003; 195: $75-81$

9. Poyser NJ, Briggs PF, Chana HS, Kelleher MG, Porter RW, Patel MM. The evaluation of direct composite restorations for the worn mandibular anterior dentition - clinical performance and patient satisfaction. J Oral Rehabil 2007; 34: 361-376.

10. Redman CD, Hemmings KW, Good JA. The survival and clinical performance of resin-based composite restorations used to treat localised anterior tooth wear. Br Dent J 2003; 194: 566-572; discussion 559.

11. Aziz K, Ziebert AJ, Cobb D. Restoring erosion associated with gastroesophageal reflux using direct resins: case report. Oper Dent 2005; 30: 395-401.

12. Vailati F, Belser UC. Full-mouth adhesive rehabilitation of a severely eroded dentition: the three-step technique. Part 1. Eur J Esthet Dent 2008; 3: 30-44.

13. Chana H, Kelleher M, Briggs P, Hooper R. Clinical evaluation of resin-bonded gold alloy veneers. J Prosthet Dent 2000; 83: 294-300.

14. Bloom DR, Padayachy JN. Increasing occlusal vertical dimension - why, when and how. Br Dent / 2006; 200: 251-256.

15. Setchell DJ. Conventional crown and bridgework. Br Dent / 1999; 187: 68-74

16. Mizrahi B. Combining traditional and adhesive dentistry to reconstruct the excessively worn dentition. Eur J Esthet Dent 2008; 3: 270-289.

17. Dicenso A, Bayley L, Haynes RB. Accessing preappraised evidence: fine-tuning the $5 \mathrm{~S}$ model into a 6 S model. Evid Based Nurs 2009; 12: 99-101.

18. Cook DI, Mulrow CD, Haynes RB. Systematic reviews: synthesis of best evidence for clinical decisions. Ann Intern Med 1997; 126: 376-380.

19. Vonville HM. Re: The new PubMed Clinical Queries Interface. [IISC mailing list] 2010 [updated 26/07/2010; cited 2010 26/07/2010]; A search filter for systematic reviews in PubMed]. Available from: https://www.jiscmail.ac.uk/cgi-bin/

Evidence-Based Dentistry (2011) 12, 55-56 doi:10.1038/sj.ebd.6400798 